\title{
Risk factors for paravalvular leak after transcatheter aortic valve replacement
}

Francesco Pollari, MD, ${ }^{\mathrm{a}, \mathrm{b}}$ Angelo Maria Dell'Aquila, MD, ${ }^{\mathrm{c}}$ Claudius Söhn, MB, ${ }^{\mathrm{d}}$ Jill Marianowicz, MB, ${ }^{\mathrm{d}}$ Pia Wiehofsky, MB, ${ }^{\mathrm{d}}$ Johannes Schwab, MD, ${ }^{\mathrm{e}, \mathrm{f}}$ Matthias Pauschinger, MD, ${ }^{\mathrm{e}}$ Wolfgang Hitzl, PhD, ${ }^{\mathrm{g}, \mathrm{h}}$ Theodor Fischlein, MD, ${ }^{\mathrm{a}}$ and Steffen Pfeiffer, $\mathrm{MD}^{\mathrm{a}}$

\section{ABSTRACT}

Objective: To assess risk factors for paravalvular leak (PVL) after transcatheter aortic valve implantation in a large single-center cohort, including measurement of aortic valve calcification using a reproducible method.

Methods: We retrospectively analyzed preoperative contrast-enhanced multidetector computed tomography scans of patients who underwent transcatheter aortic valve implantation in our center between 2009 and 2016. Calcium volume was calculated for each aortic cusp in the aortic valve, left ventricular outflow tract, and device landing zone.

Results: Overall, 539 patients were included in the study who had experience with 4 prothesis types (SapienXT [Edwards Lifesciences, Irvine, Calif] [n $=192]$, Sapien3 [Edwards Lifesciences] [ $=206$ ], CoreValve EvolutR [Medtronic, Minneapolis, Minn] [n $=44$ ], and Acurate [Symetis, Ecublens, Switzerland] $[\mathrm{n}=97])$. Median calcium volume in the device landing zone was $757 \mathrm{~mm}^{3}$, with no significant differences among the 4 prosthesis groups. None of the patients had severe PVL. The overall incidence of mild-to-moderate PVL was $15.8 \%$ (95\% confidence interval $[\mathrm{CI}], 12.8 \%-19.1 \%)$. On multivariate logistic regression, device landing zone calcification $(P=.00006$; odds ratio for an increase of $100 \mathrm{~mm}^{3}, 1.08 ; 95 \% \mathrm{CI}, 1.04-1.13$ ) and use of the CoreValve $(P=.0028$; odds ratio, $4.1 ; 95 \% \mathrm{CI}, 1.6-10$ with SapienXT as reference) prosthesis were found to be associated with mild or greater PVL. In contrast, degree of oversizing ( $P=.002$; odds ratio, $0.97 ; 95 \% \mathrm{CI}, 0.95-0.99)$, and use of Sapien3 ( $P=.00005$; odds ratio, 0.23 ; $95 \%$ CI, 0.11-0.47 with SapienXT as reference) were associated with a lower incidence of mild or greater PVL.

Conclusions: Aortic calcification volume in the device landing zone is associated with residual PVL after transcatheter aortic valve implantation. When taking calcification into account, the balloon-expandable prosthesis Sapien3 seems to be associated with a lower incidence of PVL. (J Thorac Cardiovasc Surg

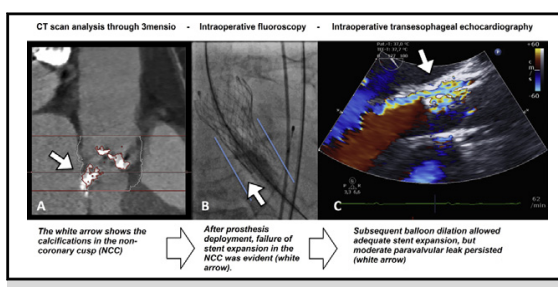

Implantation of a CoreValve prosthesis (Medtronic, Minnepolis, Minn) in a woman with an extremely calcified aortic valve.

\section{Central Message}

Device landing zone calcium volume is associated with paravalvular leak (PVL). A calcium volume with a cutoff of $1079 \mathrm{~mm}^{3}$ identifies patients with mild or greater PVL. The risk of PVL increases by $8 \%$ every $100 \mathrm{~mm}^{3}$ of calcium volume.

\section{Perspective}

Aortic valve calcification plays a role in the onset of paravalvular leak (PVL) after transcatheter aortic valve implantation (TAVI). However, most available studies suffer from limited sample size or biased determination of aortic calcification. We aimed at assessing risk factors for PVL after TAVI in a large single-center cohort, including clinical and procedural factors along with calcium volume measurement using a reproducible method.

See Editorial Commentary page 1416. 2019;157:1406-15)

\footnotetext{
From the Department of ${ }^{\mathrm{a}}$ Cardiac Surgery, ${ }^{\mathrm{d}}$ Faculty of Medicine, and ${ }^{\mathrm{e}}$ Department of Cardiology, Cardiovascular Center, and ${ }^{\mathrm{f}}$ Radiology Department, Klinikum Nürnberg, Paracelsus Medical University, Nuremberg, Germany; ${ }^{b} \mathrm{PhD}$ Program in Angio-Cardio-Thoracic Pathophysiology and Imaging, Sapienza University of Rome, Rome, Italy; ${ }^{\mathrm{c} C}$ ardiac Surgery Department, University of Münster, Münster, Germany; and ${ }^{\mathrm{g}}$ Research office (biostatistics), and ${ }^{\mathrm{h}}$ Department of Ophthalmology and Optometry, Paracelsus Medical University, Salzburg, Austria.

Received for publication March 18, 2018; revisions received July 31, 2018; accepted for publication Aug 1, 2018; available ahead of print Oct 25, 2018.

Address for reprints: Francesco Pollari, MD, Department of Cardiac Surgery, Cardiovascular Center, Klinikum Nürnberg, Paracelsus Medical University, Breslauer Str 201-90471, Nuremberg, Germany (E-mail: fpollari@gmail.com). $0022-5223 / \$ 36.00$

Copyright (c) 2018 by The American Association for Thoracic Surgery https://doi.org/10.1016/j.jtcvs.2018.08.085
}

Transcatheter aortic valve implantation (TAVI) has emerged as a new standard for percutaneous treatment of severe aortic valve stenosis in patients at intermediate and high surgical risk or who are inoperable. ${ }^{1}$ However, its wide application is yet limited by the occurrence of postoperative paravalvular leak (PVL), which portends increased mortality during follow-up. ${ }^{2}$ Aortic valve

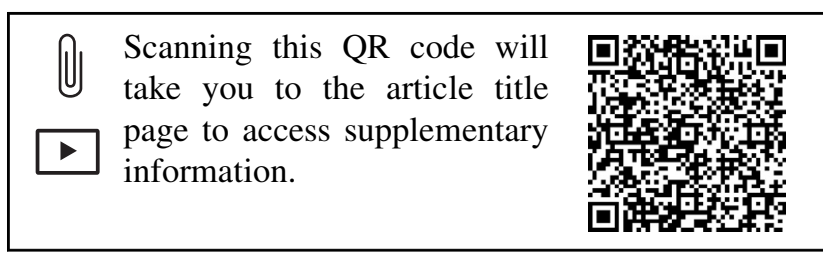




$$
\begin{aligned}
& \text { Abbreviations and Acronyms } \\
& \text { DLZ }=\text { device landing zone } \\
& \text { ECG }=\text { electrocardiography } \\
& \text { HU }=\text { Hounsfield unit } \\
& \text { LCC }=\text { left coronary cusp } \\
& \text { LVOT }=\text { left ventricular outflow tract } \\
& \text { MDCT }=\text { multidetector computed tomography } \\
& \text { NCC }=\text { noncoronary cusp } \\
& \text { PCI }=\text { percutaneous coronary intervention } \\
& \text { PVL }=\text { paravalvular leak } \\
& \text { RCC }=\text { right coronary cusp } \\
& \text { ROC }=\text { receiver operating characteristic } \\
& \text { ROI }=\text { region of interest } \\
& \text { TA }=\text { transapical } \\
& \text { TAVI }=\text { transcatheter aortic valve implantation } \\
& \text { TEE }=\text { transesophageal echocardiography } \\
& \text { TF }=\text { transfemoral }
\end{aligned}
$$

calcification has been found to be associated with $\mathrm{PVL},{ }^{3-6}$ but results from the available literature have been obtained in studies with limited sample sizes ${ }^{7}$ or influenced by several bias, including methods for calcium determination $^{8}$ or center effect in multicenter studies. ${ }^{9}$

The aim of this study was to assess risk factors for PVL after TAVI in a large single-center cohort, including aortic valve calcification as measured by contrast-enhanced multidetector computed tomography (MDCT).

\section{METHODS \\ Study Population}

We retrospectively analyzed our center experience with TAVI procedures between July 2009 and October 2016. All patients who underwent TAVI for symptomatic severe stenosis of the native aortic valve were included in the study. Severe aortic stenosis was defined in accordance with international guidelines. ${ }^{1}$ Exclusion criteria were bicuspid aortic valve, pure aortic regurgitation, and aborted procedures because of annulus diameter $>30 \mathrm{~mm}$. Overall, 659 patients were eligible for the study. However, 108 patients had not had an MDCT scan (this was not yet a standard for the first patients or the scan was performed 5 years previously and MDCT images were not retrievable from our Picture Archiving and Communication System), 4 patients had no preoperative contrast-enhanced MDCT because of severe renal impairment, 3 patients did not have electrocardiography (ECG)-triggered MDCT scans and were unsuitable for analysis, and 5 patients were treated with an experimental second-generation prosthesis. Thus, a total of 539 patients were evaluable (Figure 1). Clinical and operative data were prospectively collected in our institutional database. The following intraoperative outcomes were recorded based on the Valve Academic Research Consortium-2 recommendations ${ }^{10}$ : unplanned cardiopulmonary bypass, conversion to surgery, coronary obstruction, prosthesis valve malpositioning, second prosthesis implantation, and intraoperative percutaneous coronary intervention (PCI). All patients provided written informed consent for the use of their data anonymously, and the study was approved by our institutional review board (approval No. IRB-2017-006). The study protocol conforms to the ethical guidelines in the Declaration of Helsinki.

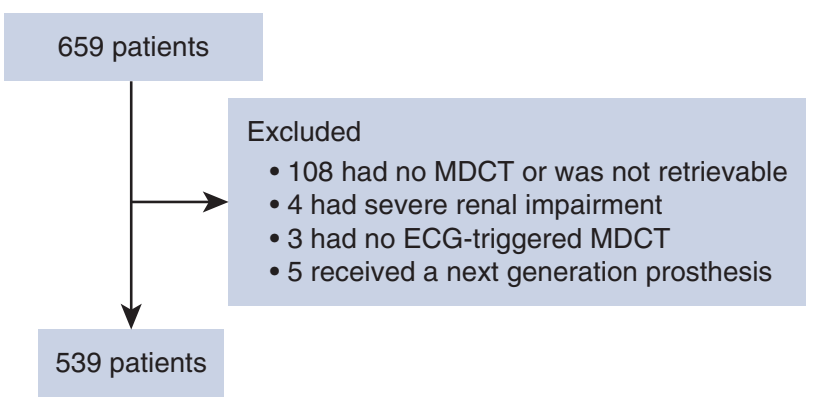

FIGURE 1. Flowchart showing the selection process of the study population. $M D C T$, Multidetector computed tomography; ECG, electrocardiography.

\section{The Heart Team}

According to international guidelines, ${ }^{1}$ indication for TAVI is discussed within a Heart Team, composed of at least a cardiologist and a cardiac surgeon evaluating patients with severe aortic valve stenosis, including those referred to our center from peripheral hospitals, private practices, or our emergency department. All patients with frailty factors who were judged inoperable or at high surgical risk (as defined by logistic European system for cardiac operative risk evaluation score $>20 \%$ ) were considered eligible for TAVI.

\section{MDCT Angiography and Calcium Quantification}

All patients underwent contrast-enhanced ECG-gated MDCT $(330 \mathrm{~ms}$ rotation, helical mode, $60 \%-70 \%$ gating, $0.6 \times 64 \mathrm{~mm}$ collimation, 50-100 mL intravenous contrast agent [Solutrast 370, Bracco Imaging Deutschland $\mathrm{GmbH}$, Konstanz, Germany] at $4 \mathrm{~mL} / \mathrm{sec}$ ) for assessment of aortic root anatomy (suitability for TAVI) and the femoral axis (suitably for transfemoral $[\mathrm{TF}]$ approach). In our center, all MDCT studies were performed with a 64-slice Somatom Definition AS (Siemens Healthcare $\mathrm{GmbH}$, Erlangen, Germany) and were analyzed by the Heart Team using 3mensio Structural Heart software (version 7.0 SP1, Medical Imaging BV, Bilthoven, the Netherlands), which allowed assessment of the basal plane (aortic annulus), defined as the virtual plane crossing the nadir of each aortic cusp in diastole (Video 1).

Calcium volume in the aortic valve was retrospectively measured using 3 mensio (Video 1). After identification of the basal plane, the lower coronary ostium was determined and the region of interest (ROI) was set before the origin of the coronary vessel. 3mensio software automatically performs aortic valve cusp delineation and detects all calcified areas for

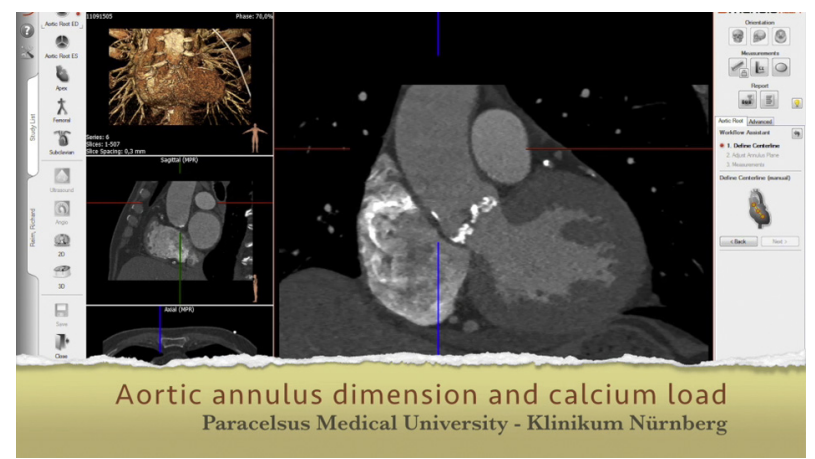

VIDEO 1. Senior author Steffen Pfeiffer explaining the importance of this study and the calcium volume assessment by 3 mensio Structural Heart software (version 7.0 SP1; Medical Imaging BV, Bilthoven, The Netherlands). Video available at: https://www.jtcvs.org/article/S0022-5223(18)32479-6/ fulltext. 

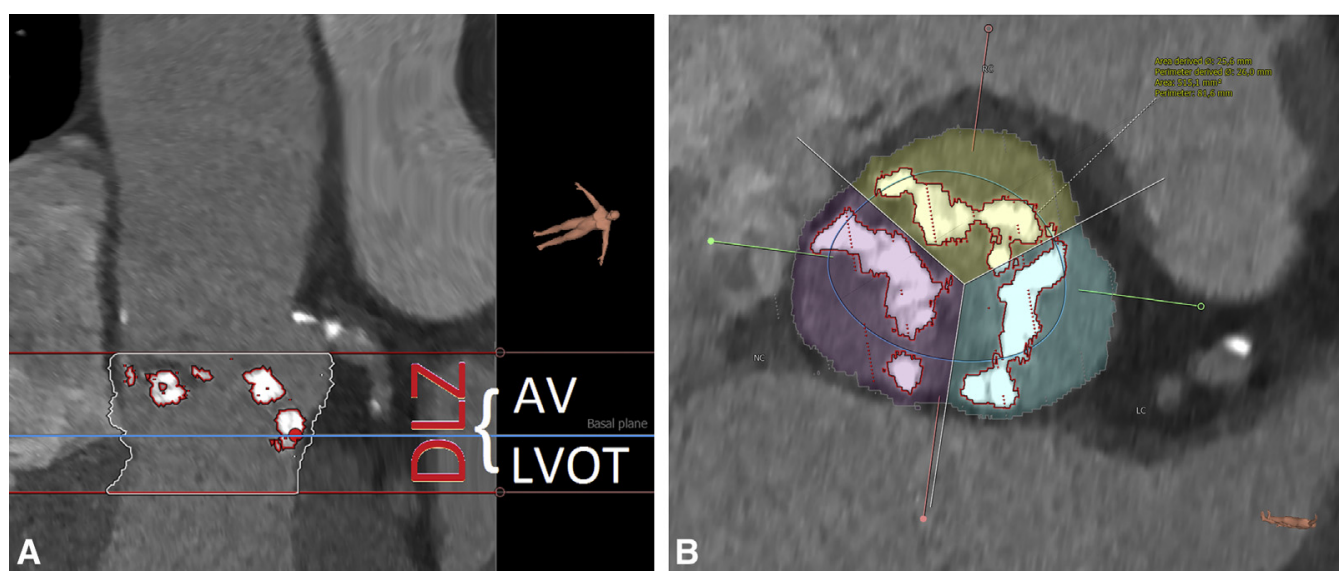

FIGURE 2. Aortic calcium volume quantification on 3mensio Structural Heart software (version 7.0 SP1, Medical Imaging BV, Bilthoven, the Netherlands). A, stretched vessel view of the aortic valve $(A V)$ and ascending aorta with highlighting of the region of interest. The blue line identifies the basal plane (aortic annulus). B, transverse view of the native AV with the 3 cusps (yellow, right coronary cusp [RC]; cyan, left coronary cusp [LC]; and magenta, noncoronary cusp $[N C])$. DLZ, Device landing zone; LVOT, left ventricular outflow tract.

the selected Hounsfield unit (HU) threshold at each of the three cusps. Correct boundary delineation of the left (LCC), right (RCC), and noncoronary cups (NCC) was checked at the coaptation point, with manual adjustment if necessary. Then, ROI was moved $10 \mathrm{~mm}$ below the basal plane in the left ventricular outflow tract (LVOT). For the purpose our study, calcium volume was assessed in 3 different ROIs: in the aortic valve, in the LVOT-these 2 ROIs were considered either as a whole or for each cusp separately, and in the device landing zone (DLZ) — defined as the sum of the first 2 (Figure 2 and Video 1). The threshold for calcium detection was set to 2 different cutoff values depending on the average $\mathrm{HU}$ of blood in the ascending aorta. For values between 130 and $300 \mathrm{HU}$, a threshold of $500 \mathrm{HU}$ was chosen, in line with previous studies. ${ }^{3,9}$ In contrast, for values between 300 and $600 \mathrm{HU}$ (46 patients), an empiric threshold of $800 \mathrm{HU}$ was chosen. Measurements of calcium volume were performed by a cardiac surgeon experienced in TAVI and trained in the use of 3mensio (FP). Interobserver variability was tested for the first 20 cases by a second cardiac surgeon (SP) and was $4.8 \%$.

The degree of over- or undersizing was calculated as prosthesis valve area (provided by the manufacturer)/MDCT annular area. Prosthesis valve area was derived according to the geometrical rule: $\mathrm{A}=\pi(\mathrm{d} / 2)^{2}$, where $d$ is the labeled prosthesis size. Aortic annulus eccentricity index was calculated as 1 - (minimal diameter/maximal diameter) based on MDCT annular measurements. ${ }^{11}$

\section{PVL Quantification}

PVL was quantified by intraoperative transesophageal echocardiography (TEE) performed by a dedicated cardiac anesthesiologist under supervision of a cardiologist. To obtain maximum accuracy, a multiwindow and multiparametric (qualitative and quantitative) approach was applied to assess PVL severity. ${ }^{12}$ The PVL was categorized as $0=$ none, $0.5=$ trace, $1=$ mild, $1.5=$ mild to moderate, $2=$ moderate, $2.5=$ moderate to severe, and $3=$ severe.

\section{Procedure}

TF-TAVI was preferred as first choice in all patients without severe peripheral artery disease and with suitable femoral axis. Alternatively, the transapical (TA-TAVI) access was used. All procedures were conducted in a hybrid operating room under fluoroscopic control (Artis Zeego System; Siemens AG), general anesthesia, periprocedural TEE, and a cardiac perfusionist with ready-to-use cardiopulmonary bypass on site. All implants were performed by a multidisciplinary team composed of at least a cardiologist (procedure leader in case of TF-TAVI) and a cardiac surgeon (procedure leader in case of TA-TAVI). Four different prostheses are routinely implanted in our center: SapienXT and Sapien3 (Edwards Lifesciences, Irvine, Calif), CoreValve/EvolutR (Medtronic, Minneapolis, Minn), and Acurate TA/NeoTF (Symetis SA, Ecublens, Switzerland). Selection of prosthesis type is agreed preoperatively with the cardiologist and cardiac surgeon on the basis of several parameters, including need for elective PCI after TAVI, annulus dimension, and distance from the aortic annulus to the coronary ostia. Definitive selection of prosthesis size is usually agreed intraoperatively by the Heart Team after evaluation of MDCT (annular perimeter-derived dimensions), TEE, and angiographic parameters (eg, contrast reflux during valvuloplasty and balloon sizing).

\section{Statistical Analysis}

Data consistency was checked and data were screened for outliers and normality by using quantile plots. Continuous variables were also tested for normality by using Kolmogrov-Smirnov test. Categorical variables are expressed as frequencies and percentages and continuous variables as mean \pm standard deviation or median and interquartile range. To assess the performance of different prosthetic valves in different calcification patterns, the study population was divided into 4 groups according to the implanted prosthesis. Differences between groups were determined by analysis of variance testing with Bonferroni correction and Kruskal-Wallis test. Cross tabulation tables with Kruskal-Wallis test for singly ordered variables. Potential risk factors for the occurrence of mild or greater PVL, including computed tomography, baseline, and operative parameters of patients were entered in the univariate and multivariate logistic regression models. The dependent variable of the logistic model was the occurrence of PVL. A univariate analysis was first performed. Variables with $P<.2$ were included in a multivariable logistic model regression analysis using stepwise selection algorithm (hierarchical forward with switching) to identify the predictors of PVL. Odds ratios with corresponding $95 \%$ confidence intervals (CIs) were computed in each model. The discrimination achieved was assessed with the $C$ statistic, which is equivalent to the area under the receiver operating characteristic curve. A generalized linear model for PVL location was built to analyze the relation between calcium distribution across the aortic cusps (based on the multinomial distribution for PVL location).

Clinical, procedural, ECG, and preoperative MDCT variables were entered into univariate analysis. A receiver operating characteristic (ROC) curve was calculated from the DLZ, allowing assessment of cutoff 
TABLE 1. Baseline and procedure-related characteristics by prosthesis*

\begin{tabular}{|c|c|c|c|c|c|c|}
\hline Characteristic & $\begin{array}{c}\text { Total } \\
(\mathrm{N}=\mathbf{5 3 9})\end{array}$ & $\begin{array}{r}\text { SapienXT } \\
(n=192) \\
\end{array}$ & $\begin{array}{c}\text { Sapien3 } \\
(\mathrm{n}=\mathbf{2 0 6})\end{array}$ & $\begin{array}{c}\text { CoreValve/EvolutR } \\
(\mathrm{n}=\mathbf{4 4})\end{array}$ & $\begin{array}{l}\text { Symetis } \\
(\mathrm{n}=97)\end{array}$ & $\begin{array}{c}P \\
\text { value }\end{array}$ \\
\hline Age (y) & $81.70 \pm 6.04$ & $81.82 \pm 6.43$ & $81.97 \pm 5.48$ & $80.09 \pm 7.72$ & $81.62 \pm 5.51$ & .30 \\
\hline Female gender & $272(50)$ & $96(50)$ & $103(50)$ & $21(48)$ & $52(54)$ & .91 \\
\hline BMI & $27.18 \pm 4.82$ & $27.07 \pm 4.75$ & $27.02 \pm 4.78$ & $27.05 \pm 4.86$ & $27.79 \pm 5.05$ & .59 \\
\hline Creatinine $(\mathrm{mg} / \mathrm{dL})$ & $1.50 \pm 0.95$ & $1.47 \pm 0.89$ & $1.47 \pm 0.79$ & $1.28 \pm 0.54$ & $1.71 \pm 1.38$ & .06 \\
\hline Creatinine clearance $(\mathrm{mL} / \mathrm{min})$ & $44.71 \pm 19.46$ & $44.67 \pm 19.34$ & $44.29 \pm 18.38$ & $50.26 \pm 20.49$ & $43.16 \pm 21.25$ & .23 \\
\hline Extracardiac arteriopathy & $145(27)$ & $50(26)$ & $55(27)$ & $8(18)$ & $32(33)$ & .31 \\
\hline Previously cardiac surgery & $111(21)$ & $47(24)$ & $33(16)$ & $10(23)$ & $21(22)$ & .21 \\
\hline Previous $\mathrm{CABG}$ & $94(17)$ & $36(19)$ & $28(14)$ & $10(23)$ & $20(21)$ & .28 \\
\hline Chronic lung disease ${ }^{\dagger}$ & $101(19)$ & $40(21)$ & $38(18)$ & $7(16)$ & $16(16)$ & .77 \\
\hline NYHA & 3.02 & 3.11 & 2.96 & 2.98 & 3.01 & .02 \\
\hline Ejection fraction $(\%)$ & $52.62 \pm 12.97$ & $53.14 \pm 13.68$ & $52.47 \pm 12.85$ & $49.05 \pm 12.30$ & $53.55 \pm 11.94$ & .24 \\
\hline Recent myocardial infarction & $16(3)$ & $10(5)$ & $4(2)$ & $0(0)$ & $2(2)$ & .13 \\
\hline Severe PHT $(>60 \mathrm{~mm} \mathrm{Hg})$ & $181(34)$ & $68(35)$ & $75(36)$ & $12(27)$ & $26(27)$ & .31 \\
\hline Additive EuroSCORE & $10.41 \pm 2.56$ & $10.59 \pm 2.65$ & $10.40 \pm 2.62$ & $9.77 \pm 2.74$ & $10.37 \pm 2.10$ & .30 \\
\hline Logistic EuroSCORE (\%) & $23 \pm 0.15$ & $24 \pm 0.16$ & $23 \pm 0.16$ & $21 \pm 0.15$ & $22 \pm 0.13$ & .41 \\
\hline EuroSCORE II $(\%)$ & $9 \pm 0.07$ & $9 \pm 0.08$ & $9 \pm 0.08$ & $8 \pm 0.06$ & $8 \pm 0.06$ & .36 \\
\hline $\mathrm{TF}$ access & $360(67)$ & $118(61)$ & $155(75)$ & $44(100)$ & $43(44)$ & $<.001$ \\
\hline Prosthesis size $(\mathrm{mm})$ & & & & & & $<.001$ \\
\hline 23 & $175(32.5)$ & $61(31.8)$ & $84(40.8)$ & 0 & $30(30.9)$ & \\
\hline 25 & $33(6.1)$ & - & - & - & $33(34)$ & \\
\hline 26 & $192(35.6)$ & $91(47.4)$ & $91(44.2)$ & $10(22.7)$ & - & \\
\hline 27 & $34(6.3)$ & - & - & - & $34(35)$ & \\
\hline 29 & $83(15.4)$ & $40(20.8)$ & $31(15)$ & $12(27.3)$ & & \\
\hline 31 & $22(4.1)$ & & & $22(50)$ & - & \\
\hline Valvuloplasty preimplant & $527(97.8)$ & $189(98.4)$ & $202(98.1)$ & $40(90.9)$ & $96(99)$ & .01 \\
\hline Implant rapid pacing & $413(76.6)$ & $192(100)$ & $206(100)$ & $4(9.1)$ & $11(11.3)$ & $<.001$ \\
\hline Balloon dilation postimplant & $184(34.1)$ & $75(39.1)$ & $53(25.7)$ & $14(31.8)$ & $42(43.3)$ & .01 \\
\hline
\end{tabular}

Values are presented as n (\%) or mean \pm standard deviation. BMI, Body mass index; CABG, coronary artery bypass graft; Chronic lung disease, use of bronchodilators; NYHA, New York Heart Association; PHT, pulmonary hypertension; EuroSCORE, European system for cardiac operative risk evaluation; TF, transfemoral. *SapienXT and Sapien3 (Edwards Lifesciences, Irvine, Calif), CoreValve/EvolutR (Medtronic, Minneapolis, Minn), and Acurate TA/NeoTF (Symetis SA, Ecublens, Switzerland). †Defined as use of bronchodilators

values defining mild or greater PVL. All reported tests were 2-sided, and $P$ values $<.05$ were considered as statistically significant. All statistical analyses in this report were performed using NCSS (NCSS 10; NCSS, LLC, Kaysville, Utah), Statistica version 13 (StatSoft, Tulsa, Okla), and PASW 23 (version 21.0 for Windows; IBM-SPSS, Armonk, NY).

\section{RESULTS}

Patient clinical and procedural characteristics are shown in Table 1, and MDCT measurements, including calcium volume are listed in Table 2, according to the implanted prosthesis. The TF access route was most frequently used for TAVI (67\% of cases). All groups had a mean logistic European system for cardiac operative risk evaluation score $>20 \%$. Calcium volume in the DLZ varied from a minimum of $17.5 \mathrm{~mm}^{3}$ to a maximum of $4523 \mathrm{~mm}^{3}$.
Significant differences among the prosthesis groups were observed in New York Heart Association class, size of prosthesis used, valve area, annulus perimeter, distance between the coronary ostia and annuli, and oversizing. Calcium volume in the DLZ and in the diverse subsectors did not significantly differ among groups.

Figure 3, $A$, and Table E1 show the incidence of PVL by prosthesis group. Overall, 199 patients $(36.9 \%)$ had an intraoperative leak (from trace to moderate). No patient presented severe or moderate to severe PVL. Patients implanted with the Sapien3 valve had the lowest incidence and degree of PVL. The distribution of calcium volume in the DLZ for patients with none, trace, mild, and moderate PVL are showed in Figure E1 according to valve prosthesis. Logistic regression model ( $C$ statistic, $0.809 ; 95 \% \mathrm{CI}$, 
TABLE 2. Multidetector computed tomography measurements by prosthesis*

\begin{tabular}{|c|c|c|c|c|c|c|}
\hline & Total & SapienXT & Sapien3 & CoreValve/EvolutR & Symetis & $\begin{array}{c}P \\
\text { value }\end{array}$ \\
\hline Annulus area $\left(\mathrm{cm}^{2}\right)$ & 4.60 (3.9 to 5.28$)$ & 4.51 (3.82 to 5.12$)$ & 4.64 (4.08 to 5.42$)$ & $5.39(4.15$ to 6.03$)$ & 4.49 (3.78 to 4.98$)$ & $<.001$ \\
\hline $\begin{array}{l}\text { Annulus perimeter } \\
(\mathrm{mm})\end{array}$ & $77.50(71.8$ to 83.5$)$ & 76.55 (70.95 to 82.8$)$ & 78.60 (72.75 to 84.3$)$ & 83.70 (74.37 to 88.77$)$ & $76.50(70.45$ to 81.35$)$ & $<.001$ \\
\hline $\begin{array}{l}\text { Distance } \\
\text { annulus-RCA } \\
(\mathrm{mm})\end{array}$ & $15.40(13$ to 18$)$ & $17.00(14.32$ to 19.2$)$ & 14.55 (12.6 to 17.2$)$ & 15.00 (12 to 17.7$)$ & $14.40(11.8$ to 17.5$)$ & $<.001$ \\
\hline $\begin{array}{l}\text { Distance } \\
\text { annulus-LCA } \\
(\mathrm{mm})\end{array}$ & $13.40(11.6$ to 15$)$ & $13.60(12$ to 15.5$)$ & $14.00(11.05$ to 15$)$ & 12.90 (11 to 15.37$)$ & $13.00(11$ to 15$)$ & .04 \\
\hline Oversizing (\%) & 12 (3.2 to 23$)$ & 15 (6.1 to 27.2$)$ & 7 (-0.65to 14.3$)$ & 34 (21.9 to 45.5$)$ & 11 (6.8 to 20.4$)$ & $<.001$ \\
\hline Eccentricity index & $0.19(0.14$ to 0.23$)$ & $0.19(0.13$ to 0.23$)$ & $0.19(0.15$ to 0.23$)$ & $0.19(0.13$ to 0.22$)$ & $0.19(0.15$ to 0.24$)$ & .51 \\
\hline $\begin{array}{l}\text { DLZ calcium } \\
\left(\mathrm{mm}^{3}\right)\end{array}$ & 757.00 (442 to 1176$)$ & 748.10 (419 to 1171$)$ & 756.10 (477 to 1174$)$ & 976.80 (561 to 1446$)$ & 649.00 (391 to 1086$)$ & .06 \\
\hline $\begin{array}{l}\text { Total calcium-AV } \\
\qquad\left(\mathrm{mm}^{3}\right)\end{array}$ & 683.00 (412 to 1082$)$ & 655.20 (409 to 1023$)$ & 698.2 (433 to 1094$)$ & 917.45 (482 to 1323$)$ & 633.60 (356 to 1073$)$ & .07 \\
\hline $\begin{array}{l}\text { LCC calcium-AV } \\
\qquad\left(\mathrm{mm}^{3}\right)\end{array}$ & $188.80(95$ to 327$)$ & $173.60(84$ to 305$)$ & 186.4 (102 to 337$)$ & 251.60 (104 to 363$)$ & $176.80(104$ to 308$)$ & .26 \\
\hline $\begin{array}{l}\text { RCC calcium-AV } \\
\left(\mathrm{mm}^{3}\right)\end{array}$ & 178.70 (89 to 312$)$ & $181.85(84$ to 313$)$ & $188.4(120$ to 303$)$ & $190.40(85$ to 417$)$ & $139.20(67$ to 296$)$ & .15 \\
\hline $\begin{array}{l}\text { NCC calcium-AV } \\
\quad\left(\mathrm{mm}^{3}\right)\end{array}$ & 289.60 (161 to 452$)$ & $273.50(155$ to 439$)$ & $290.75(171$ to 460$)$ & 390.35 (155 to 578$)$ & 276.60 (157 to 439$)$ & .05 \\
\hline $\begin{array}{l}\text { Total calcium-LVOT } \\
\qquad\left(\mathrm{mm}^{3}\right)\end{array}$ & $18.00(1.37$ to 85$)$ & $12.70(0.025$ to 77$)$ & 17.70 (2 to 68.85$)$ & $48.30(6.1$ to 190.8$)$ & 22.70 (1.6 to 91.25$)$ & .26 \\
\hline $\begin{array}{l}\text { LCC calcium-LVOT } \\
\qquad\left(\mathrm{mm}^{3}\right)\end{array}$ & 2.05 (0 to 34$)$ & 0.40 (0 to 23.82$)$ & $1.60(0$ to 31.1$)$ & $5.2(0$ to 88.57$)$ & $5.1(0.1$ to 48.45$)$ & .34 \\
\hline $\begin{array}{l}\text { RCC calcium-LVOT } \\
\left(\mathrm{mm}^{3}\right)\end{array}$ & 0.00 (0 to 1.2$)$ & $0.00(0$ to 0.1$)$ & $0.10(0$ to 2.75$)$ & 0.05 (0 to 6.87$)$ & 0.00 (0 to 0.55$)$ & .49 \\
\hline $\begin{array}{l}\text { NCC calcium-LVOT } \\
\left(\mathrm{mm}^{3}\right)\end{array}$ & $2.00(0$ to 24$)$ & $0.90(0$ to 20.75$)$ & $2.20(0$ to 24.55$)$ & $15.95(0.22$ to 62.07$)$ & $1.80(0$ to 18.6$)$ & .05 \\
\hline
\end{tabular}

Values are presented as median (interquartile range). $R C A$, Right coronary artery; $L C A$, left coronary artery; $D L Z$, device landing zone; $A V$, aortic valve; $L C C$, left coronary cusp; $R C C$, right coronary cusp; $N C C$, noncoronary cusp; $L V O T$, left ventricular outflow tract. *SapienXT and Sapien3 (Edwards Lifesciences, Irvine, Calif), CoreValve/EvolutR (Medtronic, Minneapolis, Minn), and Acurate TA/NeoTF (Symetis SA, Ecublens, Switzerland).

0.771-0.843) (Table 3), based on preoperative variables of Tables 1 and 2, identified DLZ calcification and use of CoreValve/EvolutR prosthesis as associated with mild or greater PVL. On the other hand, degree of oversizing and use of Sapien 3 were associated with a lower incidence of mild or greater PVL. The discriminating power of DLZ calcification was evaluated by $C$ statistic and ROC curve analysis. The area under the ROC curve (Figure E2) was 0.66 (95\% CI, 0.617-0.699; $P=.0001)$ for mild or greater PVL. The ROC analysis identified the cutoff value of $1079 \mathrm{~mm}^{3}$ (sensitivity $53 \%$; specificity $75 \%$ ) for DLZ calcification, above which a significantly increased risk of mild or greater PVL was observed. Differences in PVL incidence for DLZ higher or lower than $1079 \mathrm{~mm}^{3}$ are shown in Figure 3, $B$, for each prosthesis group. A DLZ calcium volume $>1079 \mathrm{~mm}^{3}$ was associated with a significantly higher incidence of mild or greater PVL in all prosthesis groups $(P<.05)$.
Among the 199 patients with PVL, data on annular leak location were missing in 33 . In the remaining 166 patients, the lowest incidence of PVL was detected in the RCC (5.4\%), which also had less calcium volume in the LVOT. PVL was located more frequently in the LCC $(59.6 \%)$, followed by the NCC $(26.5 \%)$. In the remaining $8.4 \%$ of cases, it occurred at the commissure level (LCC/NCC, $5.4 \%$; NCC/RCC, $0.6 \%$; and RCC/LCC, $2.4 \%$ ). On generalized linear model (multinomial model) no significant relations were found between PVL location and calcium distributions across the aortic cusps.

\section{Other Intraoperative Complications and Outcome}

Prosthesis migration or malpositioning occurred in 6 cases (3 SapienXT [TA access], 2 Symetis [TA access], 1 CoreValve [TF access]), seemingly unrelated to calcium volume (mean DLZ calcium, $785 \mathrm{~mm}^{3}$; range, $171-1338 \mathrm{~mm}^{3}$ ) but to a low level of oversizing (median, 


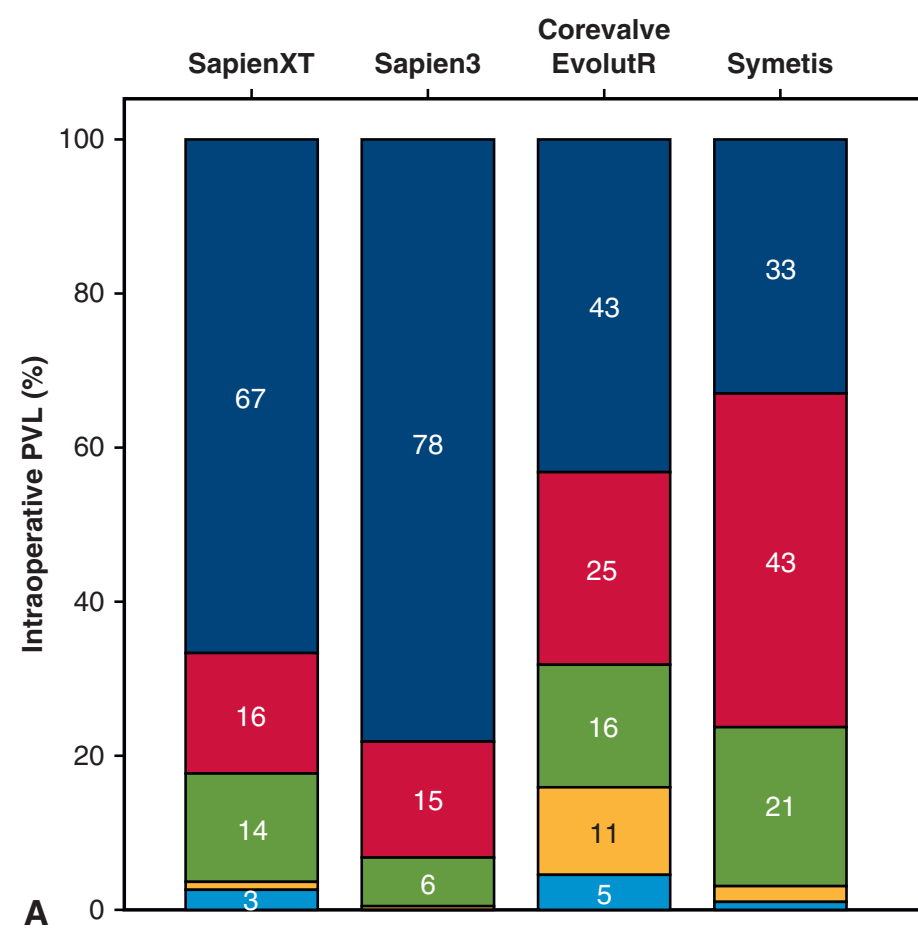
PVL none
PVL trace
$\square$ PVL mild
$\square$ PVL mild/moderate
$\square$ PVL moderate
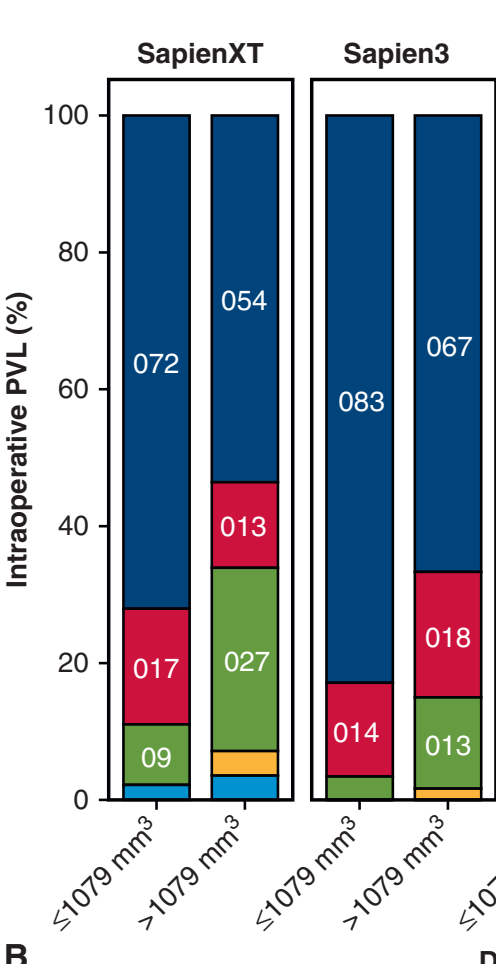

\section{CoreValve EvolutR}

Symetis

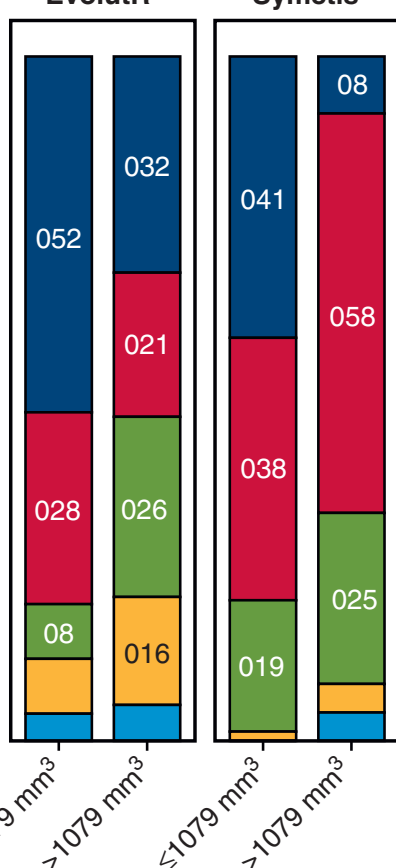
$\square$ PVL none $\square$ PVL trace $\square$ PVL mild $\square$ PVL mild/moderate

PVL moderate

\section{B}

DLZ

FIGURE 3. A, Incidence of residual paravalvular leak $(P V L)$ in the 4 prosthesis groups (blue, none; red, trace; green, mild; yellow, mild/moderate; and cyan, moderate) assessed by intraoperative transesophageal echocardiography. B, Differences in residual PVL in the 4 prosthesis groups according to device landing zone calcium volume higher or lower than the cutoff value of $1079 \mathrm{~mm}^{3}$. SapienXT and Sapien3 (Edwards Lifesciences, Irvine, Calif), CoreValve/EvolutR (Medtronic, Minneapolis, Minn), and Acurate TA/NeoTF (Symetis SA, Ecublens, Switzerland). DLZ, Device landing zone. 
TABLE 3. Independent factors for paravalvular leak at logistic regression analysis

\begin{tabular}{|c|c|c|c|c|}
\hline & \multicolumn{2}{|r|}{ Unvaried model } & \multicolumn{2}{|l|}{ Multivariate model (stepwise) } \\
\hline & $P$ value & Odds ratio (95\% Confidence interval) & Odds ratio $(95 \%$ Confidence interval) & $P$ value \\
\hline Ejection fraction $(\%)$ & .14 & $0.99(0.97-1.00)$ & - & - \\
\hline Annulus diameter - $\max (\mathrm{mm})$ & .002 & $1.14(1.05-1.24)$ & - & - \\
\hline Annulus diameter - $\min (\mathrm{mm})$ & .02 & $1.12(1.02-1.23)$ & - & - \\
\hline Annulus area $\left(\mathrm{cm}^{2}\right)$ & .001 & $1.51(1.18-1.93)$ & - & - \\
\hline Annulus perimeter $(\mathrm{mm})$ & .004 & $1.05(1.01-1.08)$ & - & - \\
\hline Oversizing $(\%)$ & .039 & $0.98(0.97-1.00)$ & $0.97(0.95-0.99)$ & .002 \\
\hline LCC calcium-AV $\left(\mathrm{mm}^{3}\right)$ & .00003 & $1.00(1.00-1.00)$ & - & - \\
\hline NCC calcium-AV $\left(\mathrm{mm}^{3}\right)$ & .00001 & $1.00(1.00-1.00)$ & - & - \\
\hline LCC calcium-LVOT $\left(\mathrm{mm}^{3}\right)$ & .054 & $1.00(1.00-1.00)$ & - & - \\
\hline NCC calcium-LVOT $\left(\mathrm{mm}^{3}\right)$ & .0003 & $1.01(1.00-1.01)$ & - & - \\
\hline Female gender* & .011 & $0.54(0.33-0.87)$ & - & - \\
\hline Dialysis (preoperative) & .19 & $0.26(0.03-1.95)$ & - & - \\
\hline TA access ${ }^{\dagger}$ & .015 & $1.79(1.12-2.88)$ & - & - \\
\hline \multicolumn{5}{|l|}{ Prosthesis $\ddagger$} \\
\hline Sapien XT ${ }^{\S}$ & - & 1 & 1 & - \\
\hline Sapien 3 & .001 & $0.34(0.18-0.65)$ & $0.23(0.11-0.47)$ & .00005 \\
\hline CoreValve/EvolutR & .019 & $2.69(1.17-6.17)$ & $4.09(1.62-10.3)$ & .003 \\
\hline Symetis & .23 & $1.44(0.80-2.62)$ & $1.29(0.68-2.43)$ & .44 \\
\hline DLZ calcium $\left(\mathrm{mm}^{3}\right) \|$ & $<.00001$ & $1.09(1.05-1.13)$ & $1.08(1.04-1.12)$ & .00006 \\
\hline
\end{tabular}

$L C C$, Left coronary cusp; $A V$, aortic valve; $N C C$, noncoronary cusp; $L V O T$, left ventricular outflow tract; $T A$, transapical; $D L Z$, device landing zone. *Reference is male. $\dagger$ Reference transfemoral. ${ }^{\ddagger}$ SapienXT and Sapien3 (Edwards Lifesciences, Irvine, Calif), CoreValve/EvolutR (Medtronic, Minneapolis, Minn), and Acurate TA/NeoTF

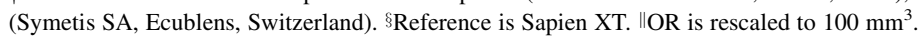

9.7\%). Three patients underwent emergent surgical aortic valve replacement following explantation of the TAVI device. Three patients underwent emergency valve-invalve implantation with good results in 2 and conversion to surgical aortic valve replacement in 1 . All 6 patients survived the procedure.

Annular rupture occurred in 2 patients (DLZ calcium of 2828 and $613 \mathrm{~mm}^{3}$, respectively, with intraprocedure death in 1 patient, and discharge to home in the other). Coronary obstruction as isolated complication (unrelated to prosthesis migration) occurred in 2 patients (DLZ calcium, 1044 and $156 \mathrm{~mm}^{3}$ [Sapien XT]), requiring emergency PCI in 1 patient and coronary artery bypass graft in the other. Overall, immediate and 30-day mortality was $0.93 \%$ $(\mathrm{n}=5)$ and $5.38 \%(\mathrm{n}=29)$, respectively.

\section{DISCUSSION}

Our study evaluated postimplant PVL occurrence and grade using a multimodality approach that included measurement of aortic valve calcification. On the basis of our results, DLZ calcification plays a key role in PVL occurrence after TAVI, and routine determination of calcium volume with a quantitative and reproducible measurement may provide additional useful information for planning interventions. In presence of extensive DLZ calcifications and increased risk of PVL, the procedural strategy should be modified accordingly, trying to reduce the burden of other contributing but controllable factors (eg, oversizing and choice of prosthesis), and CoreValve prosthesis is more vulnerable and performs less efficiently in the presence of severe calcification.

The use of MDCT has become routine for transcatheter heart valve sizing and procedure planning. ${ }^{1}$ Given the availability of improved imaging software and the widespread use of TAVI, we adopted a new approach to extract the most information from MDCT and achieve the best possible outcome.

The presence of even mild residual PVL in high-risk patients was found to be associated with a significantly worse survival compared with that of patients who did not exhibit such complication, up to 5-year follow-up. ${ }^{2}$ In intermediate-risk patients, this tendency was also observed for moderate or greater PVL. ${ }^{13}$ The incidence of mild or greater PVL varies across studies, ranging from $44 \%$ to $77 \%$, with moderate or greater PVL ranging from $3.1 \%$ to $21.6 \% .^{14,15}$ In our study, greater than mild PVL was observed in $15.76 \%$ of patients, with $1.4 \%$ experiencing moderate PVL and none severe PVL, which is significantly lower than the incidence reported in the literature. In our opinion, 2 factors may account for this 
discrepancy. First, the use of new prostheses. A direct comparison between SapienXT and Sapien3, where the latter is a further development of the former and was used in the majority of our study patients, seems to confirm that the improvements introduced in the newer generation valves (eg, annular skirt) have fulfilled the predetermined purpose of reducing PVL occurrence, as also demonstrated in the SOURCE-3 Registry. ${ }^{14}$ Second, the higher use of balloon postdilation $(34.13 \%)$. This is the result of our team's choice of low tolerance of moderate or greater PVL, which proved to be safe, with only 1 case of annular rupture among patients who underwent balloon postdilation.

Our study aimed at identifying a practical method for preprocedural calcification assessment. The critical value above which all prosthesis models were vulnerable seems to be $>1000 \mathrm{~mm}^{3}$ (reference was PVL of mild degree or greater). Despite the sensitivity and specificity of this threshold not being optimal, this finding is consistent with previous research. ${ }^{3}$ In every case, the low incidence of other intraoperative complications, apparently unrelated to the degree of calcification, confirms that TAVI remains a safe procedure.

To the best of our knowledge, this study is the largest to assess calcium volume in patients undergoing TAVI. Studies based on reproducible and quantitative methods (or dedicated software) for quantification of aortic valve calcification have so far been scant, with limited sample size or several potential biases.

In 123 patients implanted with a Sapien/SapienXT valve (23 and $26 \mathrm{~mm}$ ) prosthesis, Jilaihawi and colleagues ${ }^{4}$ tested the reliability of contrast-enhanced MDCT for calcium quantification at multiple thresholds for detection compared with the traditional Agatston scoring used for noncontrast MDCT scans. On multivariate analysis, prosthesis undersizing and presence of LVOT calcium were predictors of PVL.

In a retrospective study, Koh and colleagues ${ }^{7}$ evaluated 56 patients who underwent TAVI with TA or transaortic delivery of an Sapien valve (no longer commercially available). Calcium volume was significantly higher in patients with PVL, but no correlation was found with PVL grade. These findings were not supported by multivariate analysis.

Seiffert and colleagues ${ }^{9}$ evaluated the influence of calcium volume on PVL using a similar method to ours and reported comparable median calcium volumes $\left(619 \mathrm{~mm}^{3}\right.$ in the aortic valve and $11 \mathrm{~mm}^{3}$ in the LVOT). DLZ calcium, particularly if located in the LVOT, was predictive of PVL. In the study by Seiffert and colleagues ${ }^{9}$ a higher incidence of PVL was observed. Because this was a 2-center study, 1 possible reason accounting for this finding is a center effect, which was also identified at linear regression analysis. Another aspect that deserves consideration is the low number of implants of $23-\mathrm{mm}$ valves performed in their patients. In addition, in their study, only next-generation transcatheter aortic prostheses for TA access (eg, JenaValve [JenaValve Technology GmbH, Munich, Germany], Engager [Medtronic]) were used, equipped with a peculiar implant system. Further, no balloon-expandable Sapien3 prosthesis was used in their study, which on the contrary accounts for $38 \%$ of the prostheses used in our study and implanted via TF access in $75 \%$ of cases. Similar to the experience of Seiffert and colleagues $^{9}$ the CoreValve prosthesis was associated with a higher incidence of PVL. Although no small-sized CoreValve prostheses $(23 \mathrm{~mm}$ ) were used in our population, multivariate analysis has ruled out annular size as a risk factor for PVL. This means that the high incidence of PVL in this group cannot be explained solely by its use in large aortic annuli. Additionally, the CoreValve group had the highest degree of oversizing, which was found to be a protective factor for subsequent PVL. An explanation may lie in the peculiar radial forces of the CoreValve nitinol stent. Figure 4 shows how a severe calcification, despite 34\% oversizing, can result in a noncorrectable PVL, even after postdilatation, in a CoreValve prosthesis. It should be noted that only intraoperative TEE was evaluated because it is highly accurate in discriminating PVL from central regurgitation and our study was focused solely on the acute outcome. However, it has been demonstrated that incidence and severity of PVL after CoreValve implantation tend to diminish over time, showing a significant reduction after 1 year. ${ }^{16}$ Incidence of PVL at discharge (assessed through transthoracic echocardiography) in our series is showed in Figure E3 and Table E1. Bearing in mind the inferiority of transthoracic echocardiography with respect to the TEE, we did not observe any reduction in the incidence of mild or greater PVL.

\section{Localization of PVL}

Although our analysis confirmed that aortic calcification is crucial in determining postimplant PVL, less clear conclusions can be drawn regarding PVL location. A very low incidence of PVL was observed in the RCC. One possible explanation for this finding is that the RCC is positioned above the interventricular septum, which is probably a more stable cardiac structure allowing better sealing compared with the left and right fibrous trigone with which the LCC and NCC, respectively, are in direct continuity. However, the fact that PVL was found to be most frequently located in the LCC despite higher calcium volume along the NCC, remains unexplained. This may be due to confounding factors (eg, radial force distribution of the different stent designs) that, along with calcification, may contribute to determine the location of PVL, or a bias in reporting localization of PVL. Given that the valve systems used in our study do not provide an anatomic 


\section{CT scan analysis through 3mensio - Intraoperative fluoroscopy - Intraoperative transesophageal echocardiography}

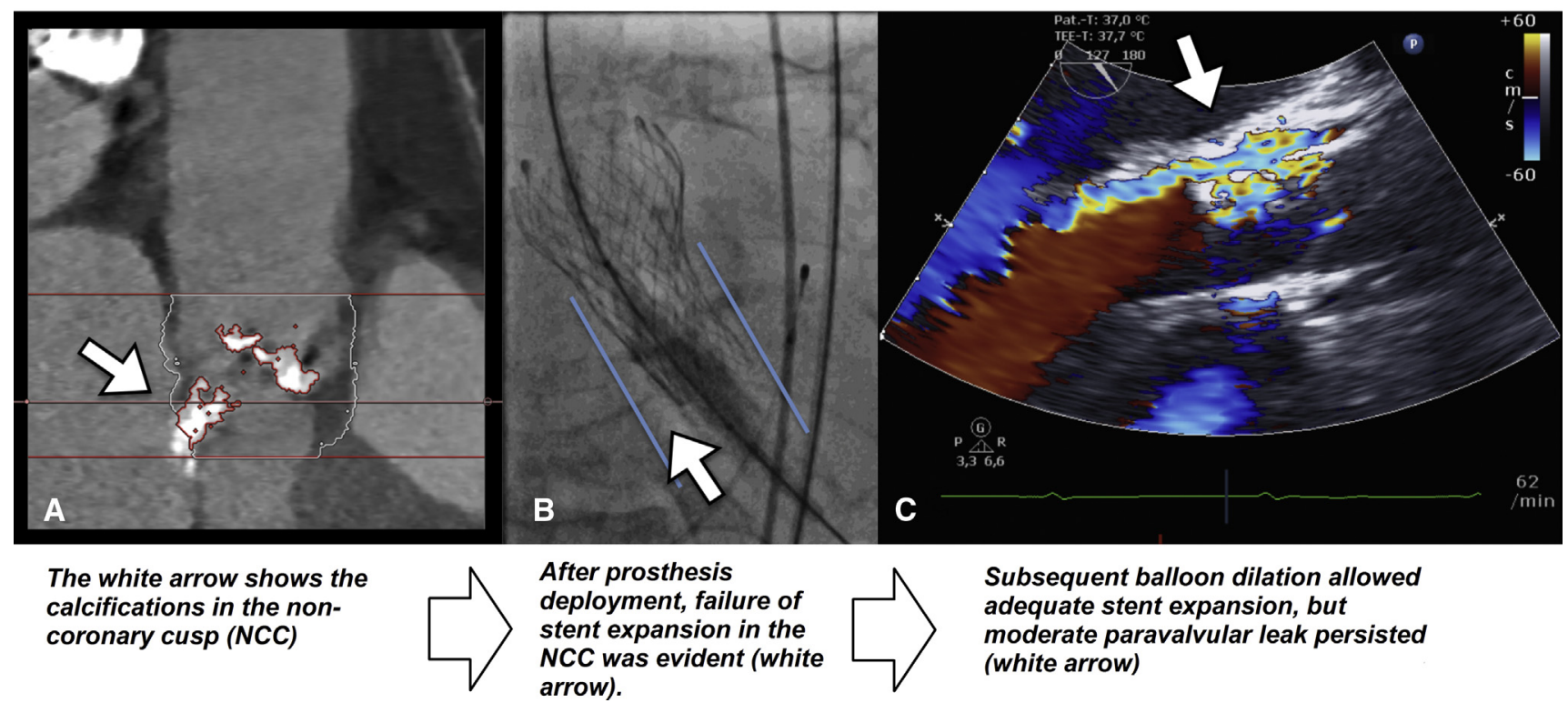

FIGURE 4. An emblematic example showing onset of paravalvular leak during implantation of a $29 \mathrm{~mm}$ CoreValve EvolutR prosthesis (Medtronic, Minneapolis, Minn) in an 82-year-old woman with extremely calcified aortic valve. A, Calcification of aortic valve on 3 mesio multidetector computed tomography scan (Structural Heart software version 7.0 SP1, Medical Imaging BV, Bilthoven, the Netherlands) (device landing zone calcium volume, $1622 \mathrm{~mm}^{3}$; noncoronary cusp [NCC]-left ventricular outflow tract calcium volume, $223 \mathrm{~mm}^{3}$; oversizing, 34\%). The white arrow shows NCC-left ventricular outflow tract. B, Intraoperative fluoroscopy: after prosthesis deployment, failure of stent expansion in the NCC was evident (white arrow). $\mathrm{C}$, Subsequent balloon dilation allowed adequate stent expansion, but moderate paravalvular leak persisted (white arrow) at intraoperative transesophageal echocardiography.

orientation of the prosthesis into the aortic annulus, the exact recognition of the native cusps is difficult after implantation. Fluoroscopy provides only a 2-dimensional projection, and the use of intraoperative 3-dimensional TEE is not routine practice in our institution. Notwithstanding this, future prospective studies using intraoperative 3-dimensional imaging are required to address the issue of PVL localization.

\section{Study Limitations}

Several limitations should be acknowledged in this study. First, the method used for assessing aortic calcification. Previous studies investigated the reliability of contrast-enhanced MDCT and different thresholds with nonenhanced MDCT. ${ }^{4}$ Unfortunately, the results of contrast-enhanced MDCT remain strongly dependent on the selected HU threshold. Indeed, the choice of testing blood HU in the ascending aorta was intended to avoid relevant mistakes deriving from the indiscriminate use of the same threshold for all study patients. The selected threshold of $500 \mathrm{HU}$ (and $800 \mathrm{HU}$ in some cases) is arbitrary and needs to be validated, although adopted in previous similar studies. ${ }^{3,4,9}$ Second, differences in prosthesis groups, where a greater expertise in balloonexpandable prostheses was likely. Third, extended calcifications may be hiding undetected bicuspid aortic valves that could be account as confounding factors. ${ }^{17}$ Fourth, the retrospective nature of our study, which calls for the need of randomized prospective studies to validate our findings. Until then, suggesting a specific prosthesis for a particular calcification pattern would be imprudent. Moreover, the importance of other perioperative complications (eg, vascular complications, stroke, and need for permanent pacemaker implantation) should not be underestimated and is currently the subject of dedicated studies from our team.

\section{CONCLUSIONS}

Aortic calcification volume in the DLZ is associated with residual PVL after TAVI. When taking calcification into account, the balloon-expandable prosthesis Sapien 3 seems to be associated with a lower incidence of PVL.

\section{Conflict of Interest Statement}

Authors have nothing to disclose with regard to commercial support.

\section{References}

1. Baumgartner H, Falk V, Bax JJ, De Bonis M, Hamm C, Holm PJ, et al 2017 ESC/EACTS guidelines for the management of valvular heart disease: The task force for the management of valvular heart disease of the European Society of Cardiology (ESC) and the European Association for Cardio-Thoracic Surgery (EACTS). Eur Heart J. 2017;38:2739-91. 
2. Mack MJ, Leon MB, Smith CR, Miller DC, Moses JW, Tuzcu EM, et al. 5 -year outcomes of transcatheter aortic valve replacement or surgical aortic valve replacement for high surgical risk patients with aortic stenosis (PARTNER 1): a randomised controlled trial. Lancet. 2015;385: 2477-84.

3. Khalique OK, Hahn RT, Gada H, Nazif TM, Vahl TP, George I, et al. Quantity and location of aortic valve complex calcification predicts severity and location of paravalvular regurgitation and frequency of post-dilation after balloon-expandable transcatheter aortic valve replacement. JACC Cardiovasc Interv. 2014;7:885-94

4. Jilaihawi H, Makkar RR, Kashif M, Okuyama K, Chakravarty T, Shiota T, et al. A revised methodology for aortic-valvar complex calcium quantification for transcatheter aortic valve implantation. Eur Heart J Cardiovasc Imaging. 2014; $15: 1324-32$

5. Ewe SH, Ng ACT, Schuijf JD, van der Kley F, Colli A, Palmen M, et al. Location and severity of aortic valve calcium and implications for aortic regurgitation after transcatheter aortic valve implantation. Am J Cardiol. 2011; 108:1470-7.

6. Leber AW, Kasel M, Ischinger T, Ebersberger UH, Antoni D, Schmidt M, et al Aortic valve calcium score as a predictor for outcome after TAVI using the CoreValve revalving system. Int J Cardiol. 2013;166:652-7.

7. Koh EY, Lam KY, Bindraban NR, Cocchieri R, Planken RN, Koch KT, et al. Aortic valve calcification as a predictor of location and severity of paravalvular regurgitation after transcatheter aortic valve implantation. Interact Cardiovasc Thorac Surg. 2015;20:345-50

8. Unbehaun A, Pasic M, Dreysse S, Drews T, Kukucka M, Mladenow A, et al. Transapical aortic valve implantation: incidence and predictors of paravalvular leakage and transvalvular regurgitation in a series of 358 patients. J Am Coll Cardiol. 2012;59:211-21.

9. Seiffert M, Fujita B, Avanesov M, Lunau C, Schön G, Conradi L, et al. Device landing zone calcification and its impact on residual regurgitation after transcatheter aortic valve implantation with different devices. Eur Heart J Cardiovasc Imaging. 2016;17:576-84.
10. Kappetein AP, Head SJ, Généreux P, Piazza N, van Mieghem NM Blackstone EH, et al. Updated standardized endpoint definitions for transcatheter aortic valve implantation: the valve academic research consortium-2 consensus document. Eur Heart J. 2012;33:2403-18.

11. Hansson NC, Nørgaard BL, Barbanti M, Nielsen NE, Yang TH, Tamburino C et al. The impact of calcium volume and distribution in aortic root injury related to balloon-expandable transcatheter aortic valve replacement. J Cardiovasc Comput Tomogr. 2015;9:382-92.

12. Pibarot P, Hahn RT, Weissman NJ, Monaghan MJ. Assessment of paravalvular regurgitation following TAVR: a proposal of unifying grading scheme. JACC Cardiovasc Imaging. 2015;8:340-60.

13. Leon MB, Smith CR, Mack MJ, Makkar RR, Svensson LG, Kodali SK, et al Transcatheter or surgical aortic-valve replacement in intermediate-risk patients. N Engl J Med. 2016;374:1609-20.

14. Wendler O, Schymik G, Treede H, Baumgartner H, Dumonteil N, Ihlberg L, et al SOURCE 3 Registry: design and 30-day results of the European postapproval registry of the latest generation of the SAPIEN 3 transcatheter heart valve. Circulation. 2017;135:1123-32.

15. Gerckens U, Tamburino C, Bleiziffer S, Bosmans J, Wenaweser P, Brecker S, et al. Final 5-year clinical and echocardiographic results for treatment of severe aortic stenosis with a self-expanding bioprosthesis from the ADVANCE Study. Eur Heart J. 2017;38:2729-38.

16. Oh JK, Little SH, Abdelmoneim SS, Reardon MJ, Kleiman NS, Lin G, et al Regression of paravalvular aortic regurgitation and remodeling of self-expanding transcatheter aortic valve: an observation from the CoreValve U.S. Pivotal Trial. JACC Cardiovasc Imaging. 2015;8:1364-75.

17. Popma JJ, Ramadan R. CT imaging of bicuspid aortic valve disease for TAVR JACC Cardiovasc Imaging. 2016:9:1159-63.

Key words: AVI, calcification, device landing zone, aortic regurgitation, transcatheter heart valve, paravalvular leak 


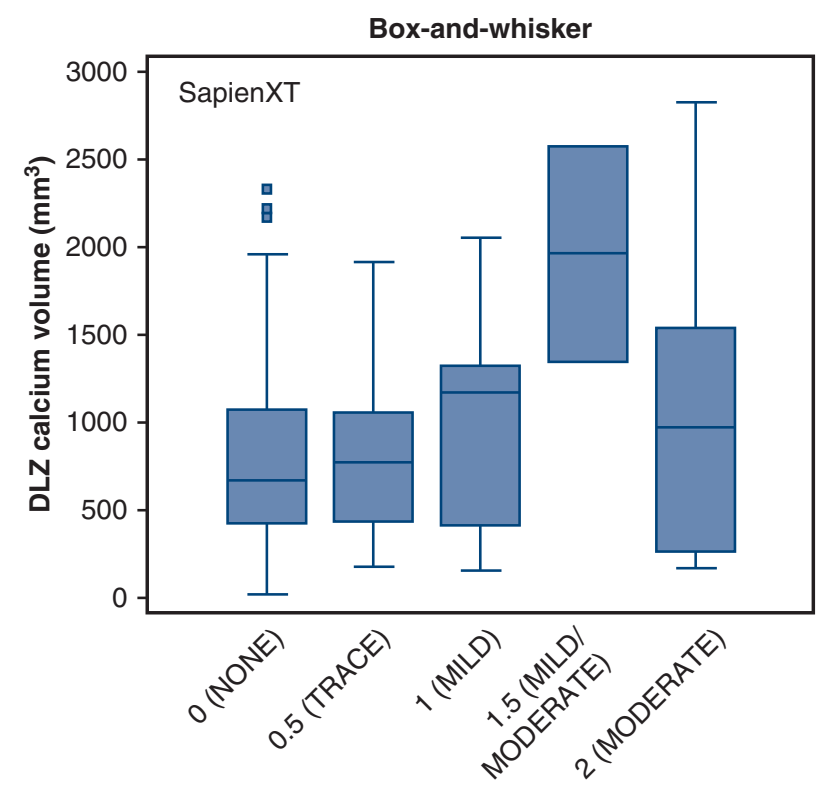

A

PVL

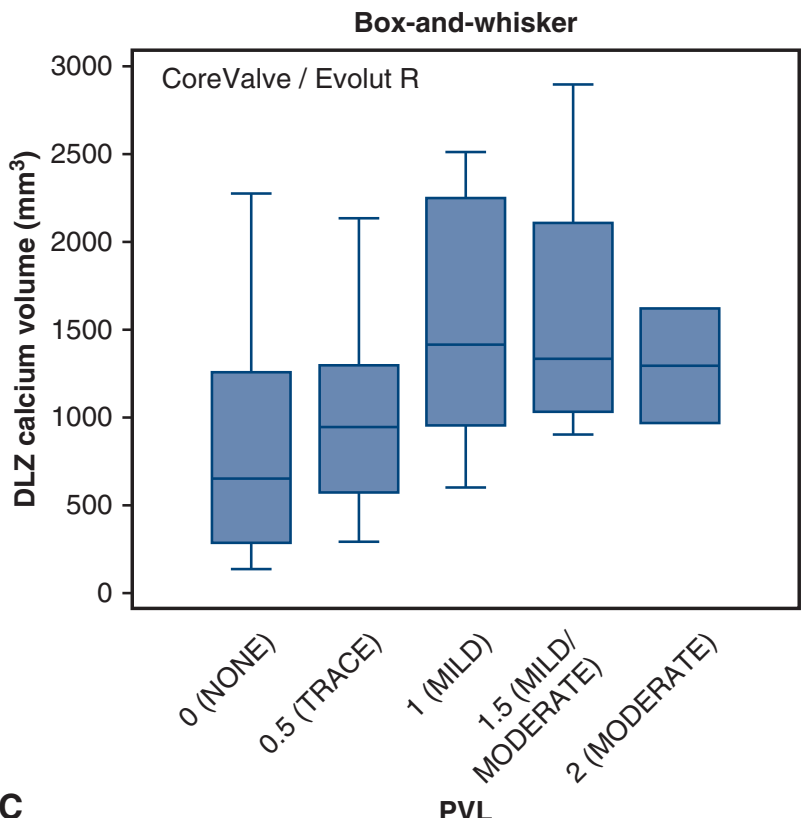

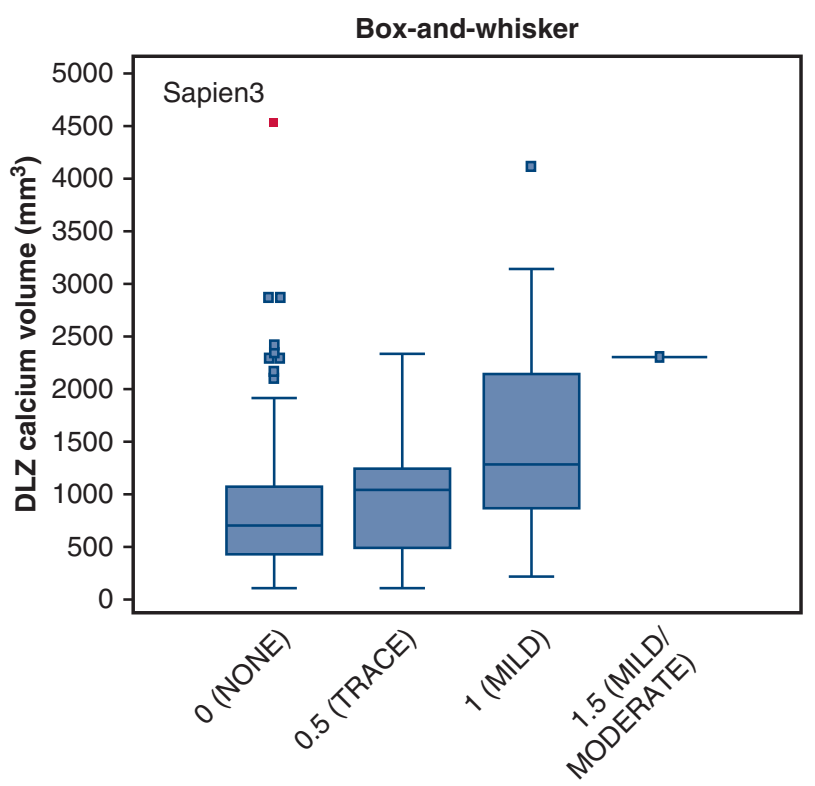

PVL

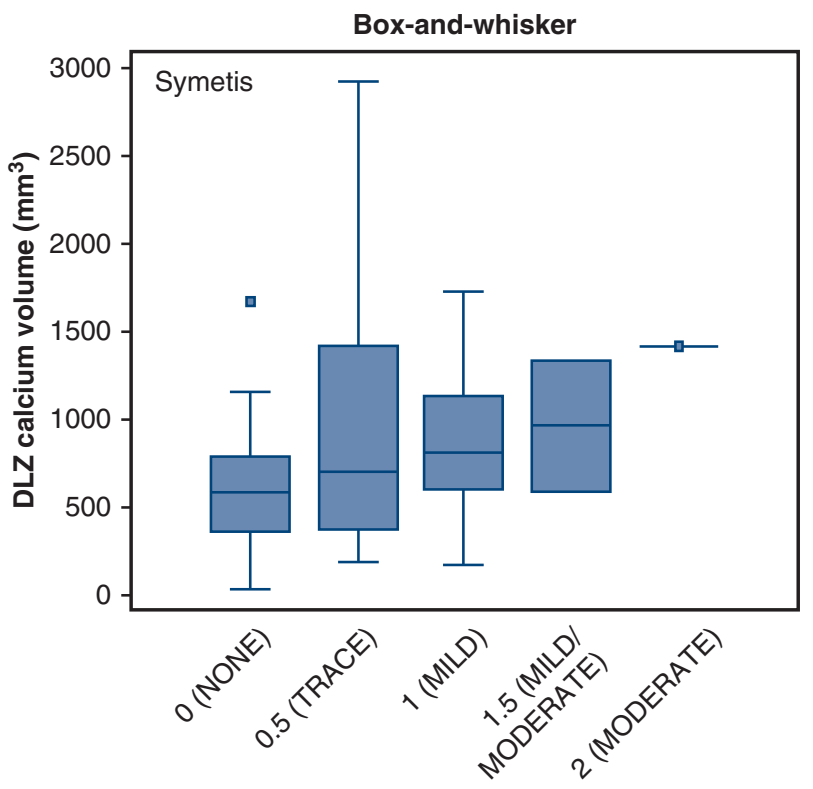

D

PVL

FIGURE E1. Side-by-side boxplot showing the distribution of calcium volume in the device landing zone (DLZ) for patients with none, mild, mild/moderate, and moderate paravalvular leak $(P V L)$ for each implanted prosthesis. A, SapienXT and (B) Sapien3 (Edwards Lifesciences, Irvine, Calif), (C) CoreValve/EvolutR (Medtronic, Minneapolis, Minn), and (D) Acurate TA/NeoTF (Symetis SA, Ecublens, Switzerland). 


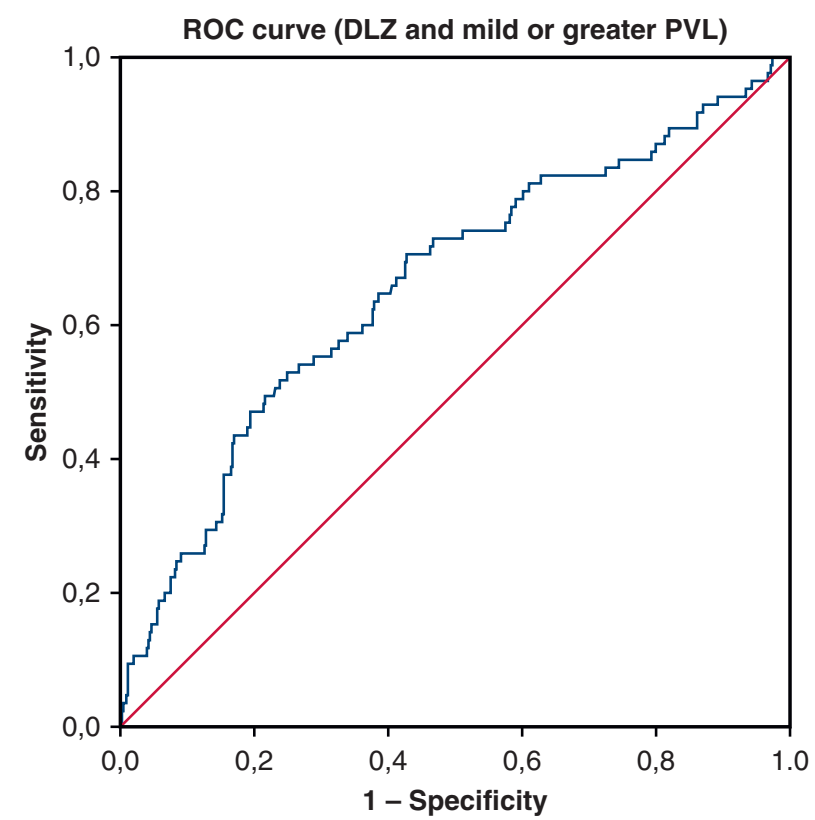

FIGURE E2. Receiver operating characteristic $(R O C)$ curve analysis for the accuracy of device landing zone $(D L Z)$ calcium in predicting mild or greater paravalvular leak $(P V L)$.

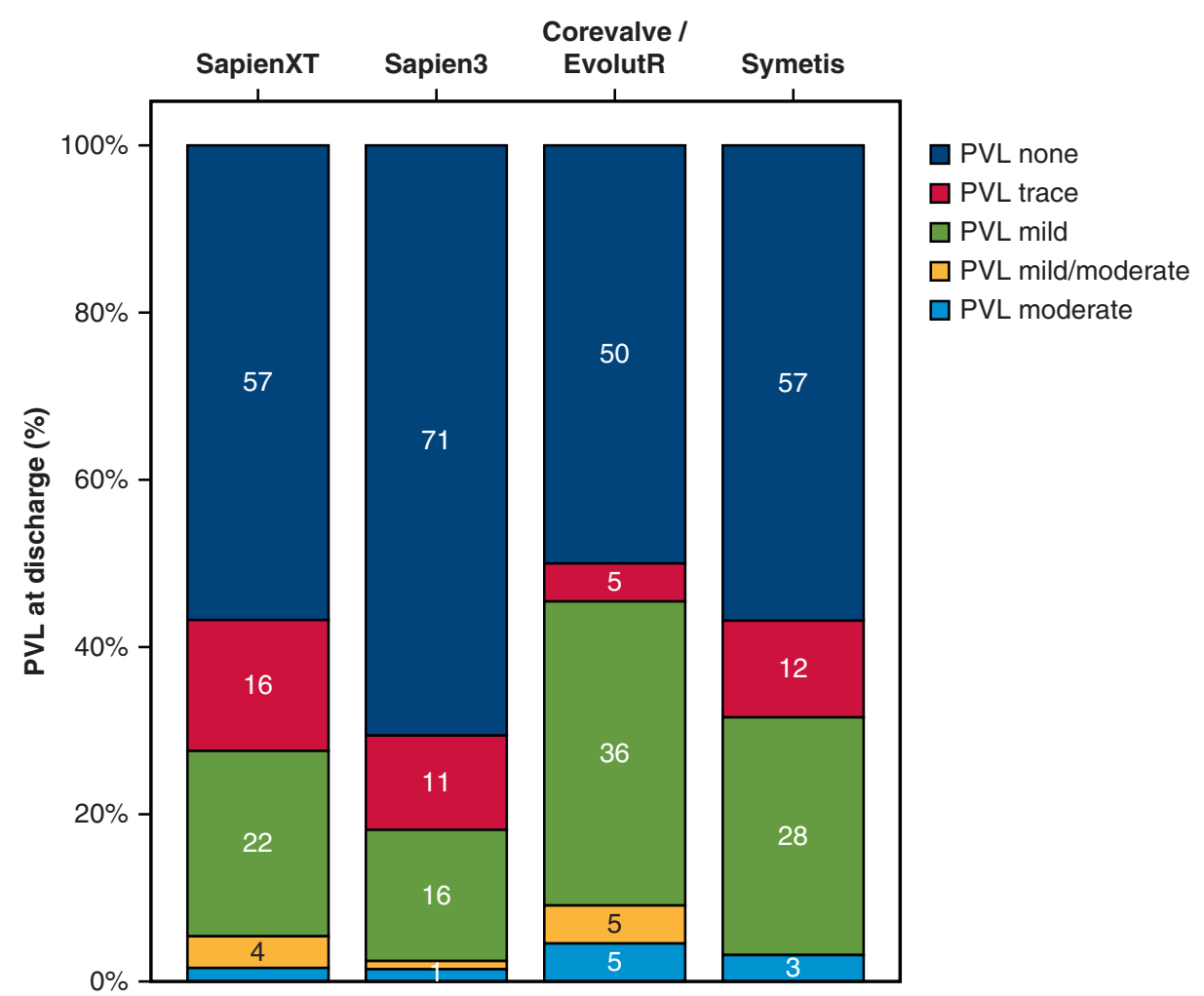

FIGURE E3. Incidence of residual paravalvular leak $(P V L)$ in the 4 prosthesis groups (blue, none; red, trace; green, mild; yellow, mild/moderate; and cyan, moderate) assessed by transthoracic echocardiography at discharge from hospital. SapienXT and Sapien3 (Edwards Lifesciences, Irvine, Calif), CoreValve/ EvolutR (Medtronic, Minneapolis, Minn), and Acurate TA/NeoTF (Symetis SA, Ecublens, Switzerland). 
TABLE E1. Incidence of residual paravalvular leak (PVL) in the 4 prosthesis groups* intraoperative and at discharge

\begin{tabular}{lrccc}
\hline & \multicolumn{4}{c}{ CoreValve/ } \\
& $\begin{array}{c}\text { SapienXT } \\
(\mathbf{n}=\mathbf{1 9 2})\end{array}$ & $\begin{array}{c}\text { Sapien3 } \\
(\mathbf{n}=\mathbf{2 0 6})\end{array}$ & $\begin{array}{c}\text { EvolutR } \\
(\mathbf{n = 4 4 )})\end{array}$ & $\begin{array}{c}\text { Symetis } \\
(\mathbf{n}=\mathbf{9 7})\end{array}$ \\
\hline PVL at end of procedure $^{\dagger}$ & & & & \\
$\quad$ Trace & 30 & 31 & 11 & 42 \\
Mild & 27 & 13 & 7 & 20 \\
Mild/moderate & 2 & 1 & 5 & 2 \\
Moderate & 5 & 0 & 2 & 1 \\
PVL at discharge + & & & & \\
None & 112 & 146 & 22 & 56 \\
Trace & 29 & 23 & 2 & 11 \\
Mild & 41 & 32 & 16 & 27 \\
Mild/moderate & 7 & 2 & 2 & 0 \\
Moderate & 3 & 3 & 2 & 3 \\
\hline
\end{tabular}

$P V L$, Paravalvular leak. *SapienXT and Sapien3 (Edwards Lifesciences, Irvine, Calif), CoreValve/EvolutR (Medtronic, Minneapolis, Minn), and Acurate TA/NeoTF (Symetis SA, Ecublens, Switzerland). ${ }^{\dagger}$ Assessed by transesophageal echocardiography. ‡Assessed by transthoracic echocardiography. 